\title{
Case Report: Familial Gastric Cancer and Chordoma in the Same Family
}

\author{
Walter Weber', Rodney J. Scott ${ }^{2}$ \\ Department of Oncology, University Clinics Basel, CH 4031, Switzerland; 2Discipline of Medical Genetics, Faculty of Health, University of Newcastle NSW 2308 \\ and the Hunter Medical Research Institute Newcastle, Australia
}

Key words: stomach cancer, HNPCC, E-cadherin, chordoma

Corresponding author: Rodney J. Scott, Faculty of Health, University of Newcastle NSW 2308 and the Hunter Medical Research Institute Newcastle, Australia,e-mail: rodney.scott@newcastle.edu.au

Submitted: 10 May 2005

Accepted: 15 May 2005

\begin{abstract}
Gastric cancers are the second most common malignancy in the world and represent a major burden to all societies even though the incidence of disease is decreasing in the industrialized world. The aetiology of the disease is complex and is believed to be primarily due to environmental factors but a small proportion of cases are recognised as being associated with genetic factors. Two inherited forms of stomach cancer have been identified, one which is associated with familial clusterings of stomach cancer and the other being a subgroup of families that belong to hereditary non polyposis colorectal cancer (or Lynch syndrome). In this report we present a small nuclear family which is unusual in that there is a clustering of malignancy which includes stomach cancer, colorectal cancer and chordoma. Genetic analysis failed to reveal any causative mutation in genes associated with HNPCC or in E-cadherin. Together, the clinical picture in this family may indicate that other genetic factors are behind this family's clustering of malignancy.
\end{abstract}

\section{Introduction}

Gastric cancers represent the second most common malignancy worldwide although the incidence of disease appears to be diminishing in the industrialized world. Gastric cancers are morphologically heterogeneous with three types; diffuse gastric cancer, a glandular (or intestinal) type and a mixture of diffuse and intestinal disease.

The causes of gastric cancer are both environmental and genetic or a mixture of both. Relatively recently a definitive genetic cause of gastric cancer (mutations in the E-cadherin gene) has been identified, first in a large New Zealand Maori kindred [1] and subsequently in other gastric families [2]. Patients harbouring mutations in the E-cadherin gene tend to present with diffuse disease whereas no genetic factors have been implicated in familial aggregations of intestinal gastric cancer.

An alternative genetic cause of stomach cancer in association with a variety of other epithelial cancers is hereditary non polyposis colorectal cancer (HNPCC). This entity is characterized by early onset colorectal cancer and a variety of other epithelial malignancies including endometrial cancer and stomach cancer. The genetic basis of this condition is a breakdown of DNA mismatch repair due to mutations in genes controlling this process. Currently four genes have been isolated and associated with HNPCC, hMLH1, hMSH2, hMSH6 and hPMS2. Both hMSH2 and hMSH6 reside on chromosome 2, 
hMLH1 is on chromosome 3 and hPMS2 is on chromosome 7 (for review see Niessen et al 2004 [3]).

Chordomas are rare slow growing bone tumours that are believed to arise out of notochord remnants [3]. They tend to occur at the base of the skull and have a relatively benign histological appearance. Despite their benign appearance chordomas have infiltrative properties that are difficult to control. There is a slight preponderance for males to be affected with an overall male to female ratio of about 1.7:1. The preponderance of males becomes more striking in patients with sacral chordomas where the male to female ratio approaches $3: 1$. Little is known about the molecular basis of chordomas, as there appears to be no gross chromosomal abnormality or any other distinct distinguishing feature. Two genetic loci have been identified. The first indication of a genetic basis for chordoma came from linkage studies that revealed a gene locus on chromosome 1 [4]. A second locus was identified in a small series of families linked to chromosome 7q33, which has revealed a number of potential candidate genes [5].

In this report we have identified a small family that is characterized by stomach cancer and the presence of chordoma in one of three siblings all of whom have succumbed to malignancy.

\section{Patients and methods}

The family history of disease is as follows: The proband presented at the age of 56 years with a poorly differentiated adenocarcinoma of the cecum without the presence of adenomatous polyps. At the time of excision the tumour had metastasized to three lymph nodes. The patient was found to have widespread

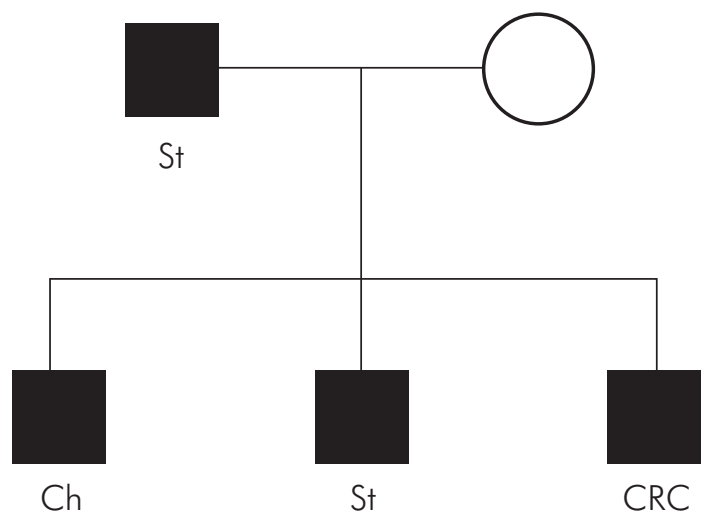

Fig. 1. Pedigree of the family. St = stomach cancer; $\mathrm{Ch}=$ chordoma; $\mathrm{CRC}=$ colorectal cancer. Squares represent males, circles females metastatic disease at the age of 60 years and died one year later. The only other remarkable finding with respect to this patient was the congenital aplasia of the left thigh. The family history of the proband revealed a history of gastrointestinal cancer (see Fig. 1).

The father of the proband was diagnosed with stomach cancer at the age of 67 years. The tumour was diagnosed as an undifferentiated mucinous carcinoma with signet ring cells which had at the time of surgery already spread to the liver.

The eldest brother of the patient was diagnosed at the age of $71 / 2$ years with a malignant chordoma at the base of his skull and died soon after. The tumour was situated between the clivus and pons which gave rise to typical neurological signs. The tumour had impinged on the optic nerve resulting in severe atrophy, especially on the right side. In addition there were multiple liver metastases.

The second brother was diagnosed with adenocarcinoma of the stomach originating in the cardia. The tumour was an undifferentiated mucinous type interspersed with signet ring cells, similar to that of the father. At the time of diagnosis the disease was found to have become widespread with metastases to the vertebra, liver, adrenals and lungs.

\section{DHPLC analysis}

The entire coding sequences of hMSH2, hMLH1 and $\mathrm{E}$-cadherin including the intron/exon boundaries were screened for mutations by DHPLC analysis. Any unusual conformers were further assessed by direct DNA sequencing.

Polymerase chain reaction (PCR) amplification for DHPLC analysis was performed using primers specific for hMSH2 and hMLH1 as described previously (Holinski-Feder et al 2001). The reaction consisted of 1.0 $\mu \mathrm{M}$ each primer, $1 \cup$ Platinum Taq (Gibco-BRL), 2-5 mM $\mathrm{MgCl}_{2}$ and $200 \mu \mathrm{M}$ each dNTP.

PCR amplification was achieved by an initial denaturation at $94^{\circ} \mathrm{C}$ for 5 min followed by 14 cycles of $94^{\circ} \mathrm{C}$ for $1 \mathrm{~min}, 7^{\circ} \mathrm{C}$ touchdown range for $1.5 \mathrm{~min}$ and $72^{\circ} \mathrm{C}$ for $2 \mathrm{~min}$, then 20 cycles using an annealing temperature $0.5^{\circ} \mathrm{C}$ lower than the bottom of the touchdown range. The annealing step was performed as a touchdown protocol with a $7^{\circ} \mathrm{C}$ range, decreasing $0.5^{\circ} \mathrm{C} /$ cycle over 14 cycles. This was followed by a final extension step at $72^{\circ} \mathrm{C}$ for $10 \mathrm{~min}$, a final denaturation step at $95^{\circ} \mathrm{C}$ for $5 \mathrm{~min}$ and a slow annealing step from $95^{\circ} \mathrm{C}$ to $65^{\circ} \mathrm{C}$ over $30 \mathrm{~min}$ to promote heteroduplex 
formation. The PCR was performed on a PCR express (Hybaid) instrument equipped with a heated lid to avoid the use of mineral oil.

DHPLC analysis was performed using a Varian Helix system (Varian Inc., Walnut Creek, CA). PCR products $(2-5 \mu l)$ were injected directly into a DNA Eclipse (Hewlett Packard) or Helix (Varian) column and eluted from the column using an increasing acetonitrile gradient and a column oven temperature suitable for each exon of hMSH2, hMLH1 and E-cadherin (actual temperatures available on request). Heteroduplexes formed during PCR of a heterozygote sample were detected as an additional peak eluting before the homoduplex peak. The detection of heteroduplexes was made simpler with the use of DHPLC review software supplied from Varian. The predicted melting temperatures of the double stranded DNA products were obtained by using the DHPLC-MELT program available from http://www.insertion.stanford.edu/melt.html (for details see Tables $1 \mathrm{a}$ and $1 \mathrm{~b}$ ).

For each segment a negative control fragment (amplified from DNA isolated from a normal healthy donor who had no family history of disease) was run through the denaturing column at the non-denaturing temperature of $50^{\circ} \mathrm{C}$. The $50^{\circ} \mathrm{C}$ peak profile was then compared to the Stanford melting temperature profile of the respective fragment as well as three $1^{\circ} \mathrm{C}$ increments on either side of predicted melting temperature. Partially denatured conditions were established when a shift in retention time of at least or equal to 30 seconds across a $1{ }^{\circ} \mathrm{C}$ increment range was made. The optimal melting temperature was always taken as the higher temperature, under partially denaturing conditions that did not exhibit profile degradation.

\section{DNA sequencing}

All heteroduplexes were subject to DNA sequencing to determine the precise genetic change on a semiautomated sequencing unit (model 310, Perkin-Elmer Applied Biosystems Division, Foster City, CA) using dideoxy. Sequencing of the PCR products was performed using version 1 BIGDYE dideoxy sequencing Ready Rxn kit (Perkin-Elmer, Foster City, CA).

\section{Results}

The family depicted in Fig. 1 conforms to the Amsterdam II criteria where other epithelial malignancies can replace colorectal cancer. The presence of two gastric cancers is unusual and could be suggestive of familial gastric cancer due to mutations in E-cadherin.
There was no material available for immunohistochemistry or microsatellite instability testing. A DNA sample was available from the proband which was subjected to mutation analysis. Since the family adhered to the Amsterdam II criteria initially hMSH2 and hMLH1 mutation analysis was undertaken. No mutations were identified in the coding sequence of either hMSH2 or hMLH1 including the intron/exon boundaries.

Since there were two individuals diagnosed with gastric cancer a further mutation screen was undertaken in the E-cadherin gene but no deleterious changes were identified.

\section{Discussion}

The failure to identify mutations in hMLH1, hMSH2 or E-cadherin suggests that there are likely to be other genetic factors underlying the disease in this family. There is nevertheless, the possibility that a mutation was missed in one of these three genes since deletion analysis was not undertaken nor was it possible to do so as there was insufficient genetic material to allow this to occur. Furthermore, since the patients succumbed to their diseases several decades ago it is unlikely that immunohistochemistry or microsatellite instability testing could be performed to assess the probability of this family belonging to the entity of HNPCC. E-cadherin was a likely candidate by virtue of the presence of signet ring cells within the two stomach cancers.

There remain several possibilities with respect to what may have occurred within this small family. First, it remains possible that this is indeed an HNPCC family not only because there may be mutations in either hMLH1 or hMSH2 but also we did not examine hMSH6 or hPMS2. The hPMS2 gene remains a likely candidate as it has been associated with recessively inherited cases of Turcot's syndrome [9]. In addition, hPMS2 resides on chromosome 7 and is surrounded by pseudogenes, some of which are expressed albeit at much lower levels than wild type hPMS2. Since a new locus for chordoma has also been identified on chromosome 7 there remains the possibility that in this family these two findings are not unrelated. Unfortunately, we may never know the answer to this since there is insufficient remaining material to study from the proband and the tumour samples taken from the other family members are no longer available. With respect to the father of the proband we do not know if the congenital aplasia of the left thigh was related to disease in this family. 
In summary, this family represents not only a challenge with respect to the identification of a genetic predisposition but also, if the family members were alive today, for genetic counselling.

\section{References}

1. Guilford P, Hopkins J, Harraway J, McLeod M, McLeod N, Harawira P, Taite H, Scoular R, Miller A and Reeve AE. $\mathrm{E}$-cadherin germline mutations in familial gastric cancer. Nature 1998; 392: 402-405.

2. Gayther SA, Gorringe KL, Ramus SJ, Huntsman D, Roviello F, Grehan N, Machado JC, Pinto E, Seruca R, Halling K, MacLeod P, Powell SM, Jackson CE, Ponder BA and Caldas C. Identification of germ-line E-cadherin mutations in gastric cancer families of European origin. Cancer Res 1998; 58: 4086-4089.

3. Niessen RC, Sijmons RH, Berends MJ, Ou J, Hofstra RM and Kleibeuker JH. Hereditary non-polyposis colorectal cancer: identification of mutation carriers and assessing pathogenicity of mutations. Scand J Gastroenterol Suppl. 2004; (241): 70-77.

4. Miozzo M, Dalpra L, Riva P, Volonta M, Macciardi F, Pericotti S, Tibiletti MG, Cerati M, Rohde K, Larizza L and Fuhrman Conti AM. A tumor suppressor locus in familial and sporadic chordoma maps to 1p36. Int J Cancer 2000; 87: 68-72.

5. Kelley MJ, Korczak JF, Sheridan E, Yang X, Goldstein AM and Parry DM. Familial chordoma, a tumor of notochordal remnants, is linked to chromosome 7q33. Am J Hum Genet 2001; 69: 454-460.

6. Osborne LR, Herbrick JA, Greavette T, Heng HH, Tsui LC and Scherer SW. PMS2-related genes flank the rearrangement breakpoints associated with Williams syndrome and other diseases on human chromosome 7. Genomics 1997; 45: 402-406.

7. Holinski-Feder E, Muller-Koch Y, Friedl W, Moeslein G, Keller G, Plaschke J, Ballhausen W, Gross M, Baldwin-Jedele K, Jungck M, Mangold E, Vogelsang H, Schackert HK, Lohsea P, Murken J and Meitinger T. DHPLC mutation analysis of the hereditary nonpolyposis colon cancer (HNPCC) genes hMLHI and hMSH2. J Biochem Biophys Methods 2001; 47: $21-32$.

8. Muta H, Noguchi M, Kanai Y, Ochiai A, Nawata H and Hirohashi $\mathrm{S}$. E-cadherin gene mutations in signet ring cell carcinoma of the stomach. Jpn J Cancer Res 1996; 87: 843-848.

9. De Vos M, Hayward BE, Picton S, Sheridan E and Bonthron DT. Novel PMS2 pseudogenes can conceal recessive mutations causing a distinctive childhood cancer syndrome. Am J Hum Genet 2004; 74: 954-964. 